\title{
The Parental Bond and Alcohol Use Among Adolescents: The Mediating Role of Drinking Motives
}

\author{
Martina Smorti and Silvia Guarnieri \\ Faculty of Education, Free University of Bozen, Bolzano, Italy
}

\begin{abstract}
Background: Alcohol use and alcohol-related problems represent a significant health concern. Few empirical researches focused on understanding the interrelationships and links between the parental bond, drinking motives, and alcohol use during adolescence.
\end{abstract}

Objectives: The present study examined the relation-ships between a supportive parental bond, drinking motives, and alcohol use, with a focus on the role of mediation.

Methods: The sample comprised 298 adolescents, aged from 16 to 20 years. The technique of structural equation modelling (SEM) was used to assess the direct and indirect effects of the parental bond on alcohol use among adolescents through motives for drinking.

Results: The relationship between the parental bond and frequency of alcohol use by adolescents was not mediated by any motives for drinking, neither for males nor females. Regarding the relationships be-tween the parental bond and quantity of adolescent alcohol consumption, findings for females showed sig-nificant indirect effects of maternal bond on alcohol quantity, when coping, enhancement, and social drink-ing motives were entered as mediator variables. Rather, paternal bond did not predict drinking quantity, not even indirectly. On the contrary, results for males indicated that the parental bond was neither directly nor indirectly associated with adolescent alcohol use.

Conclusions/Importance: Mothers are the relational fulcrum of the family, while fathers seem to main-tain a more peripheral position. Gender differences are discussed on the basis of the different cultural and parental socialisation processes that operate for male and female adolescents.

\footnotetext{
Keywords parental bond, drinking motives, alcohol use,
} adolescence, gender differences

\section{INTRODUCTION}

Alcohol use and alcohol-related problems represent a significant health concern. Heavy alcohol use has been consistently associated with serious adverse consequences and health problems affecting individual drinkers and their surrounding communities (Gmel, Rehm, \& Kuntsche, 2003; Hingson, Zha, \& Weitzman, 2009; Perkins, 2002; Turrisi, Mallett, Mastroleo, \& Larimer, 2006).

However, the Italian drinking culture is different from that of other sociocultural contexts (Graziano, Bina, Giannotta, \& Ciairano, 2012), where a precocious initia-tion to alcohol has been related to alcohol misuse and alcoholrelated problems (e.g., Tucker, Orlando, \& El-lickson, 2003). In Italy drinking is part of everyday life. The onset of alcohol consumption usually occurs dur-ing preadolescence or adolescence, within the family con-text during weekday meals (Cavallo, Lemma, Borraccino, Dalmasso, \& Zambon, 2006). This precocious onset of alcohol use in the family is not associated with subse-quent drinking problems, while the initiation of drink-ing outside the family and drinking outside the family is linked to subsequent drinking problems (Ciairano, Moli-nengo, Bonino, Miceli, \& van Schuur, 2009; DiGrande, Perrier, Lauro, \& Contu, 2000). In spite of the tradi-tional Italian drinking habits, some studies (ISTAT, 2010) have reported that recently there has been a significant increase in alcohol consumption among Italian adoles-cents. Further, heavy episodic drinking is also becom-ing widespread among Italian young adults (D'Alessio, Baiocco, \& Laghi, 2006).

Since initiation to alcohol use and excessive drinking usually occur during adolescence (Johnston, O'Malley, Bachman, \& Schulenberg, 2004) it is crucial to establish prevention efforts in this period of the lifespan.

Scholars have shown that the quality of the adolescent-parent relationship (Beck, Boyle, \&

We thank all participants in this study for their time. We would also like to thank Sarah L. Barker for her review of the English translation. Address correspondence to Martina Smorti, Faculty of Education, Free University of Bozen, Viale ratisbona 16, Bressanone 39042, Italy; E-mail:martina.smorti@unibz.it 
Boekeloo, 2004; Patock-Peckham, Cheong, Balhorn, \& Nagoshi, 2001; Patock-Peckham \& Morgan-Lopez, 2006) and motives for drinking (Ham \& Hope, 2003; Kuntsche, Knibbe, Gmel, \& Engels, 2006) have a great impact on the development or prevention of adolescents' alcohol use. Nevertheless, there is insufficient empirical research focused on understanding the interrelationships and links between the parental bond, drinking motives, and alcohol use during adolescence. The present study therefore examined these links, with a particular focus on mediation (parental bond $\rightarrow$ drinking motives $\rightarrow$ alcohol use).

\section{The Parental Bond and Alcohol Use}

The family, and particularly the relationship between adolescents and their parents, is one of the most vital so-cial contexts for adolescent development. Based on the literature showing that parental qualities are crucial to the healthy development of adolescents, scholars (Parker, 1989, Parker, Tupling, \& Brown, 1979) have isolated two basic components of parental socialisation, which relate to the dimensions of parental care and parental control. The first dimension involves the demonstration of support to the adolescent by providing emotional warmth and it is opposed to a parenting style characterised by indifference and neglect. The second parenting attribute involves encouragement of adolescents' dependence on parents and it is opposed to a parenting style typified by encourage-ment of autonomy and independence. The family bond has repeatedly been shown to be a key risk factor for fre-quent and excessive drinking among adolescents (Labrie

\& Sessoms, 2012; McArdle et al., 2002; Thomas, Reifman, Barnes, \& Farrell, 2000). Poor relations with par-ents, high family conflict, less restrictive parental rules, or insufficient monitoring by parents have been associated with subsequent adolescent alcohol use or alcohol problems (Barnow, Schuckit, Lucht, John, \& Freyberger, 2002; Choo \& Shek, 2013; Crawford \& Novak, 2002; Dishion, Nelson, \& Bullock, 2004; Laghi, Baiocco, Lonigro, Capacchione, \& Baumgartner, 2012; Vermeulen-Smit, Ter Bogt, Verdurmen, Van Dorsselaer, \& Vollebergh, 2012). In contrast, a good quality adolescent-parent relationship is associated with a lower risk of alcohol use by adoles-cents (Kuntsche \& Silbereisen, 2004; Turrisi, Wiersma,

$\&$ Hughes, 2000). Furthermore, strong bonds with parents promote and reflect the adolescent's adoption of con-ventional social norms and values (Bell, Forthun, \& Sun, 2000). The internalisation of such norms and values, in turn, guards against engagement in deviant behaviors. In sum, parents who are supportive and attentive to their adolescent's behavior, appear to reduce the likelihood of heavy drinking patterns in their offspring. Altogether, these findings suggest that the parental bond influences both the frequency and quantity of adolescents' alcohol use.

In addition, it is possible that family factors impact in different ways on male and female adolescents. Few studies have examined gender differences in parenting experiences. There is evidence that female adolescents experience higher levels of control from their parents than do their male counterparts (Barnes, Reifman, Farrell, \& Dintcheff, 2000; Borawski, Ievers-Landis, Lovegreen, \& Trapl, 2003; Li, Stanton, \& Feigelman, 2000. On the contrary, there is conflicting evidence about whether, and how, adolescents' gender moderates the link between parenting and alcohol use. In relation to this, some studies showed that the associations be-tween parenting variables and adolescents' alcohol use were stronger for males than for females (Barnes et al., 2000; Borawski et al., 2003; Griffin, Botvin, Epstein, Doyle, \& Diaz, 2000). Other researchers reported that negative correlations between family attachments and al-cohol use were stronger for females than males (Bahr, Marcos, \& Maughan, 1995; Schinke, Fang, \& Cole, 2008). Finally, other findings indicate no gender differ-ences in the link between parenting and adolescent well-being (Adalbjarnardottir \& Rafnsson, 2001).

\section{Drinking Motives and Alcohol Use}

On the basis of the Motivational Model of Alcohol Use (Cox \& Klinger, 1988), drinking motives can be classified according to two underlying dimensions, which reflect the source (internal or external) and the valence (positive or negative) of the outcomes individuals expect to achieve by drinking. With respect to source, a teenager might drink to achieve an internal reward, such as enhancement of a desired internal emotional state, or an external reward, such as social approval or acceptance. With respect to valence, an adolescent might drink to obtain a positive outcome or to avoid a negative outcome. Crossing these two dimensions yields four specific drinking motives: coping, which refers to drinking to cope with negative emotions (internal, negative reinforcement); conformity, which refers to drinking to avoid social rejection (external, negative reinforcement); enhancement, which refers to drinking to enhance positive mood or wellbeing (internal, positive reinforcement); and social, which refers to drinking to obtain social rewards (external, positive reinforcement).

Motivations are important risk factors for alcoholrelated behaviors. Drinking motives are the most proximal antecedents of alcohol use (Ham \& Hope, 2003; Kuntsche et al., 2006). Kuntsche et al. (2006) found that most adolescents reported drinking for social motives, some indicated enhancement motives, and only a few reported drinking for coping motives. Likewise, conformity motives are often reported by adolescents and young adults, and are likely to weaken with maturity (Cooper, 1994). Mostly young people drink for social facilitation or to get into a party mood, social motives tend to be related to moderate drinking (Kairouz, Gliksman, Demers, \& Ad-laf, 2002; Kassel, Jackson, \& Unrod, 2000; Read, Wood, Kahler, Maddock, \& Palfai, 2003). On the contrary, drinking as a result of enhancement or coping or conformity motives has often been associated with heavy alcohol use and alcohol-related problems (Cooper, Agocha, \& Sheldon, 2000; Grant, Stewart, O’Connor, Blackwell, \& 


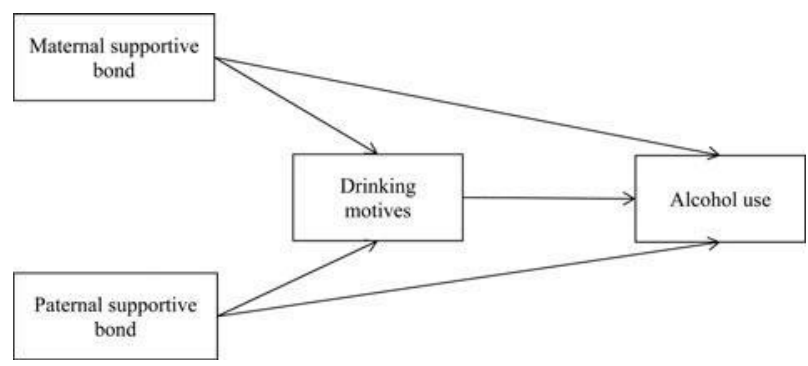

FIGURE 1. Hypothesized mediation model.

Conrod, 2007; Labouvie \& Bates, 2002; McNally, Palfai, Levine, \& Moore, 2003).

\section{Drinking Motives as a Mediator Variable}

A review of the aforementioned literature highlighted the great importance of the parental bond on adolescent alcohol consumption. On the other hand, drinking motives are the most proximal factor to alcohol use. Despite this knowledge in the field, few empirical studies have examined the links between these three factors simultaneously, and above all the relationship between parentadolescent relationships and drinking motives. In relation to this, Labrie \& Sessoms (2012) suggested that securelyattached adolescents were less likely to endorse drinking motives compared to their less securely attached peers.

From a theoretical standpoint, motivational theories generally support the view that adolescents' perceptions about their parents' parental practices are related to their motivational attitudes and beliefs (Deci \& Ryan, 2000; Grolnick, Deci, \& Ryan, 1997). Further, according to social cognitive learning theory (Bandura, 1986), within parent-adolescent relationships, adolescents may not only form beliefs about positive and negative consequences of drinking, but also more general societal and individual values and expectations about their own behaviors, which influence their drinking behavior. It is therefore theoretically hypothesised that parents shape adolescents' alcohol use, indirectly, via cognitive factors, such as drinking motives. Therefore, although this theoretical assumption of mediation is plausible, there are hardly any formal examinations of mediation in the literature.

\section{STUDY AIMS}

The general purpose of the present study was to anal-yse whether drinking motives mediated the effect of the parental bond on alcohol use. More specifically, the present research aimed to analyse: (a) the direct relation-ship between the maternal and paternal bond and the fre-quency and quantity of adolescent alcohol use and (b) the potential mediating role of drinking motives (coping, en-hancement, social, and conformity) in the relationship be-tween the parental bond and adolescent alcohol use, sep-arately for male and female adolescents (Figure 1).

It was hypothesised that drinking motives would play a significant mediating role in the relationship between the parental bond and adolescent alcohol use. Neverthe- less, given that drinking is typically integrated into everyday life in the Italian culture and adolescents' alcohol consumption also often occurs within the family context, during weekday meals, we expected that Italian parents influence above all the quantity of adolescent alcohol use rather than the drinking frequency. For this reason, we expected that both the direct and indirect relationships between the parental bond and quantity of adolescent alco-hol use would be stronger than the relationships between the parental bond and frequency of adolescent alcohol use. Finally, given the mixed findings on gender differences in relation to the link between parenting and adolescent adjustment, no hypotheses were made in this area.

Given that previous research on parenting has typically focused primarily on mothers (Roche, Ahmed, \& Blum, 2008) and has tended not to examine the role of each parent independently, one aim of the present study was to investigate the unique contribution of the maternal and paternal parent-adolescent bond to adolescent alcohol use. For this reason, the hypothesised model was tested simultaneously for the adolescent's relationship with his or her mother and father. Nevertheless, since mothers typically play a central role in the parent-adolescent relationship, especially in the Italian culture (Carra \& Marta, 1995; Rosnati, 1996; Scabini, 2000), we expected that both the direct and indirect relationships between the ma-ternal bond and alcohol use would be stronger than the relationships between the paternal bond and alcohol use.

\section{METHOD}

\section{Participants and Procedure}

The initial sample consisted of 375 adolescents (157 males, 218 females) aged from 16 to 20 years $(\mathrm{M}=18.73$; $\mathrm{SD}=$ 1.11), living in Bolzano's province (northeastern Italy) and attending different high schools (50\% lyceums, 50\% vocational schools) and universities (65.2\% Faculty of Psychology, 24\% Faculty of Education, and 10.8\% Faculty of Architecture). All the high schools and universities selected, agreed to take part in the study. Formal consent from educational authorities, parents, and students were required in accordance with Italian law and the ethical code of the Professional Psychologists Association. Data were collected anonymously in the classroom during or-dinary school hours. Students enrolled in the schools were then randomly selected and 93\% completed the question-naire (4\% were absent the day of questionnaires adminis-tration and 3\% did not obtain parental or individual con-sent to participate).

To be included in the present study, participants had to: (1) have both parents living; (2) be drinkers. The question used to differentiate drinkers and non-drinkers in terms of lifetime alcohol consumption was "Have you ever drunk an alcoholic beverage?" Responses were $1=$ never; 2 = only once; and $3=$ more than once. Drinkers were de-fined as adolescents who had drunk alcohol more than once. Most participants reported that both their parents were alive (99.4\% of mothers and $97.4 \%$ of fathers) and that they had drunk more than once (90.8\%). The present 
study sample was therefore reduced to those respondents who reported that both their parents were alive and that they met the study's criterion for being a drinker.

The final sample included 298 adolescents (133 males, 164 females), aged from 16 to 20 years $(\mathrm{M}=18.62$; $\mathrm{SD}=$ 1.14). Of these, $37 \%$ of participants attended high schools (49\% lyceums, $51 \%$ vocational schools) and $63 \%$ universities (64.8\% Faculty of Psychology, 24.4\% Faculty of Education, and $10.8 \%$ Faculty of Architecture). The majority of participants $(93 \%)$ were currently living with both their parents. All participants came from families of middle or high socioeconomic status and more than $70 \%$ of adolescents reported that both their parents had a high school diploma or university degree.

\section{Measures \\ Parental Bond}

The Italian version (Bonaiuto, Perucchini, \& Pierro, 1997) of the Parental Bonding Instrument (PBI, Parker et al., 1979) was used to measure adolescent per-ceptions of the relationships with their father and mother. PBI consisted of 21 items assessing the follow-ing three dimensions: Care (11 items), represented by warmth and involvement in one extremity and indiffer-ence and rejection in the other, Encouragement toward autonomy (6 items), characterized by the increase in per-sonal autonomy, and Overprotection (4 items) that can be defined as an excess of control or negation of psycholog-ical autonomy. An example of an item scored on the care domain is "Could make me feel better when I was upset"; an item scored in the encouragement toward autonomy do-main is "Let me decide things for myself"; and an item scored on the overprotection domain is "Tried to control everything I did." Participants were required to respond to items, rating on a 4-point Likert scale ( $0=$ Very unlike; $3=$ Very like), for mothers and fathers separately. Scores for each domain represent the sum total of domain items and could range from 0 to 33 in parental care, $0-18$ in parental encouragement toward autonomy, and $0-12$ on parental overprotection. For the present study, internal consistency coefficients (Cronbach's alpha) were .89 and .89 for Care,

.74 and .75 for Encouragement toward autonomy, and .71 and .68 for Overprotection for mother and father, respec-tively.

\section{Drinking Motives}

The Italian version (Zogmaister \& Castelli, 2011) of the Drinking Motives Questionnaire Revised (DMQ-R, Cooper, 1994) was employed to assess motivation for drinking among adolescents. The scale is a 20 -item selfreport measure based on Cox \& Klinger's (1988) fourfactor model of motives to drink alcohol. Items describe Coping (internal, negative), Enhancement (internal, positive), Social (external, positive), and Conformity (exter-nal, negative) motives. Each factor includes five items such as, "Because it helps you when you feel depressed or nervous" (Coping), "Because you like the feeling" (En-hancement), "Because it helps you enjoy a party" (Social), and "Because your friends pressure you to drink" (Con- formity). For each item, participants rated the relative frequency of drinking associated with each of 20 motives to drink on a 6-point Likert scale $(1=$ almost never/never; $6=$ almost always/always), with higher scores indicating stronger motives. Total score is derived by the sum of all the items that make up each subscale and could range from 5 to 30 . For the present study, internal consistency coefficients (Cronbach's alpha) were .89 for Coping, .92 for Enhancement, .81 for Social, and .76 for Conformity.

\section{Alcohol Use}

The Italian version (Bonino, Cattelino, \& Ciairano, 2005) of the Health Behavior Questionnaire (Jessor, Donovan, \& Costa, 1992) was employed to collect data on health-risk behaviors. The questionnaire investigates various as-pects of adolescents' daily lives. Our study was based on responses to selected questions regarding alcohol use.

\section{Drinking Frequency}

Participants rated two questions, asking about their consumption of different types of alcohol (alcoholic beverages such as beer and wine, and strong alcoholic beverages), to measure the overall frequency of their drinking of these beverage types during the past 6 months. For both questions, participants rated on a 6-point Likert scale $(1=$ Never; $2=$ Once in the last 6 months; $3=$ Once a month; $4=2-3$ times a month; $5=$ Once a week; $6=$ More than twice a week). A total score was computed by averaging the items. Higher scores indicated higher drinking fre-quency. Internal consistency coefficient (Cronbach's al-pha) was .73.

\section{Drinking Quantity}

Participants rated three questions, asking about the number of drinks (beer, wine, and strong alcoholic beverages) consumed per drinking day, to measure the overall quan-tity of drinking. For both questions, participants answered on a 6-point Likert scale $(1=$ Less than a glass; $2=1$ glass; $3=2-3$ glasses; $4=4-6$ glasses; $5=7-8$ glasses; $6=9$ or more glasses). A total score was derived by the sum of all items. Higher scores indicated higher drinking quantity. Internal consistency coefficient (Cronbach's al-pha) was .70.

\section{RESULTS}

\section{Preliminary Analyses}

A series of factorial analyses with the three dimensions of the PBI were conducted pre-emptively in order to obtain a single score for the quality of the maternal and pater-nal bond to include in the regression equation, separately for the mother and father versions. Principal axis factor-ing was selected as the method of extraction and factor scores were computed and used in subsequent analyses (Barbaranelli, 2007).

The correlation analyses between the three dimensions of the mother and father PBI versions showed that overprotection dimension correlated negatively with the care and autonomy dimensions, for both the maternal and pa- 
TABLE 1. Correlations between PBI dimensions

\begin{tabular}{lccc}
\hline PBI & Care & Autonomy & Overprotection \\
\hline Care & - & $.323^{* *}$ & $.330^{* *}$ \\
Autonomy & $-.261^{* *}$ & - & $.413^{* *}$ \\
Overprotection & $.354^{* *}$ & $.447^{* *}$ & - \\
\hline
\end{tabular}

Note. Coefficients below diagonal are relative to the mother PBI dimensions, those above the diagonal are relative to father PBI di-mensions.

${ }^{*}=p<.05 ;{ }^{* *}=p<.01 ;$ two-tailed.

ternal bond (see Table 1). For this reason, the overprotection score was reversed before factorial analyses were conducted, in order to obtain loadings with the same sign on the hypothetical common factor.

If a single factor emerged from the factorial analyses, it would be characterised by warm and affectionate parental behaviors as well as attitudes that encouraged autonomy in adolescent development and which sought to obstruct their adolescents' activities and private space as little as possible. A higher score on this dimension would be as-sociated with a positive and supportive parenting bond. Given these supportive characteristics, a factor of this kind could be named supportive bond.

Results from factor analyses indicated that the three di-mensions of the mother and father PBI versions all loaded onto a single factor.

In relation to the mother version, care, encouragement toward autonomy, and low overprotection levels ac-counted for $57 \%$ of the total variance. Moreover, the three dimensions' loadings for care, encouragement toward au-tonomy, and low overprotection were .68, .76 , and .82 , respectively. The factor was named maternal supportive bond.

Similarly, concerning the father version, the three dimensions (with the reversed overprotection dimension scores) accounted for $57 \%$ of the total variance. For the factor that was named paternal supportive bond the three

TABLE 2. Means and SDs for variables of interest (maternal supportive bond, paternal supportive bond, drinking motives, and alcohol use) by gender

\begin{tabular}{lcr}
\hline & $\begin{array}{c}\text { Male } \\
\text { M (SD) }\end{array}$ & \multicolumn{1}{c}{$\begin{array}{c}\text { Female } \\
\text { M (SD) }\end{array}$} \\
\hline Maternal supportive bond & $-.12(.79)$ & $.06(.80)$ \\
Paternal supportive bond & $-.01(.77)$ & $-.01(.80)$ \\
Drinking motives & & \\
$\quad$ Coping & $9.10(4.77)$ & $9.26(4.86)$ \\
$\quad$ Enhancement & $13.86(6.44)$ & $11.64(6.27)$ \\
$\quad$ Social & $15.28(5.28)$ & $13.34(4.58)$ \\
$\quad$ Conformity & $6.72(2.37)$ & $6.46(2.24)$ \\
Alcohol use & & \\
$\quad$ Drinking frequency & $3.88(1.34)$ & $3.63(1.43)$ \\
$\quad$ Drinking quantity & $7.53(3.27)$ & $5.29(2.67)$ \\
\hline
\end{tabular}

Note. Maternal and Paternal supportive bond factor scores derived by factorial analyses. dimensions' loadings for care, encouragement toward au-tonomy, and low overprotection were $.71, .77$, and .78 , re-spectively.

In addition, descriptive statistics (Table 2) and preliminary Pearson correlation analyses (Table 3) were calculated to determine the univariate relations among study variables, separately for males and females.

For females, results showed significant negative associations between both maternal and paternal supportive bond and drinking motives and drinking quantity, and not significant associations between parental supportive bond and drinking frequency. Further, for males, results showed not significant associations between both maternal and pa-ternal bond and drinking motives, drinking frequency, and drinking quantity.

Given that mediation can be said to occur when the independent variable significantly affects the mediators (Baron \& Kenny, 1986), we tested meditational models only for females.

\section{Mediation Analyses}

The technique of structural equation modelling (SEM), using Mplus versus 5.21 statistical program (Muthen' \& Muthen,' 1998/2007), was applied to investigate the hypothesized model reported in Figure 1 (MacKinnon, Fairchild, \& Fritz, 2007). Separate models were tested us-ing the four drinking motives - coping, enhancement, so-cial, and conformity - as mediator variables and alcohol frequency and alcohol quantity as the criterions.

Before testing the models, we conducted a preliminary analysis designed to test the normality of all the vari-ables of interest (maternal supportive bond, paternal sup-portive bond, drinking motives, and alcohol use) (Fox, 2008). Analyses revealed a non-normal distribution for some dimensions, which showed asymmetry and a kur-tosis greater than \pm 1 (Marcoulides \& Hershberger, 1997; Muthen' \& Kaplan, 1985). For this reason, subsequent analyses were conducted using the robust method Max-imum Likelihood Estimates, (MLM; Muthen' \& Muthen,' 1998/2007).

Mediation analysis results for drinking frequency revealed that both maternal and paternal bond were directly and indirectly unrelated to drinking frequency via drink-ing motives. Therefore, no mediation was supported for females when the criterion was drinking frequency.

Concerning drinking quantity, both maternal and paternal bond were directly and indirectly unrelated to drinking quantity, when conformity was entered as mediator variable. In this case, no mediation was supported for females.

On the contrary, mediation was found for female adolescents, when coping, enhancement, and social were en-tered as mediator variables.

In particular, in the model, when coping motive was entered as mediator variable, maternal supportive bond was unrelated directly to drinking quantity. Rather, maternal bond had a significant indirect effect on drinking quan-tity, through coping motives $(\beta=-.11)$. In particular, maternal bond was strongly negatively related to coping, which, in turn, was significantly associated with adoles- 
TABLE 3. First-order correlations between variables of interest (maternal supportive bond, paternal supportive bond, drinking motives, and alcohol use)

\begin{tabular}{|c|c|c|c|c|c|c|c|c|}
\hline & 1 & 2 & 3 & 4 & 5 & 6 & 7 & 8 \\
\hline 1. Maternal supportive bond & - & $.77^{* *}$ & $-.39^{* *}$ & $-.33^{* *}$ & $-.35^{* *}$ & $-.23^{* *}$ & -.12 & $-.18^{*}$ \\
\hline $\begin{array}{l}\text { 2. Paternal supportive bond } \\
\text { Drinking motives }\end{array}$ & $.56^{* *}$ & - & $-.27^{* *}$ & $-.25^{* *}$ & $-.25^{* *}$ & $-.23^{* *}$ & -.07 & $-.16^{*}$ \\
\hline 3. Coping & -.15 & -.15 & - & $.59^{* *}$ & $.62^{* *}$ & $.39^{* *}$ & $.34^{* *}$ & $.29^{* *}$ \\
\hline 4. Enhancement & -.01 & -.05 & $.48^{* *}$ & - & $.75^{* *}$ & .15 & $.46^{* *}$ & $.44^{* *}$ \\
\hline 5. Social & -.07 & -.03 & $.54^{* *}$ & $.71^{* *}$ & - & $.40^{* *}$ & $.40^{* *}$ & $.38^{* *}$ \\
\hline $\begin{array}{l}\text { 6. Conformity } \\
\text { Alcohol use }\end{array}$ & -.12 & -.15 & $.60^{* *}$ & $.36^{* *}$ & $.42^{* *}$ & - & .08 & .12 \\
\hline 7.Drinking frequency & -.11 & -.04 & $.30^{* *}$ & $.45^{* *}$ & $.44^{* *}$ & .11 & - & $.36^{* *}$ \\
\hline 8. Drinking quantity & -.01 & -.04 & $.18^{*}$ & $.33^{* *}$ & $.36^{* *}$ & .06 & $.51^{* *}$ & \\
\hline
\end{tabular}

Note. Coefficients below diagonal are relative to males, those above the diagonal are relative to

females. ${ }^{*}=p<.05 ;{ }^{* *}=p<.01$; two-tailed.

cent' drinking quantity. Finally, paternal supportive bond was not related either directly or indirectly to drinking quantity (see Figure 2). About $9 \%$ of the variance in drink-ing quantity was explained by the indirect effect of mater-nal supportive bond.

In addition, when enhancement motive was entered as mediator variable, maternal supportive bond was unrelated directly to drinking quantity. Rather, maternal bond had a significant indirect effect on drinking quantity, through enhancement motives $(\beta=-.15)$. Specifically, maternal bond was strongly negatively related to enhancement, which, in turn, was significantly associated with adolescent' drinking quantity. Finally, paternal sup-portive bond was not related either directly or indirectly to drinking quantity (see Figure 3). About $20 \%$ of the vari-ance in drinking quantity was explained by the indirect effect of maternal supportive bond.

Lastly, when social motive was entered as mediator variable, maternal supportive bond was unrelated directly to drinking quantity. Rather, maternal bond had a significant indirect effect on drinking quantity, through social motives $(\beta=-.14)$. In particular, maternal bond was strongly negatively related to social, which, in turn, was significantly associated with adolescent' drinking quantity. Finally, paternal supportive bond was not related either directly or indirectly to drinking quantity (see Figure 4). About $15 \%$ of the variance in drinking quantity was explained by the indirect effect of maternal supportive bond.

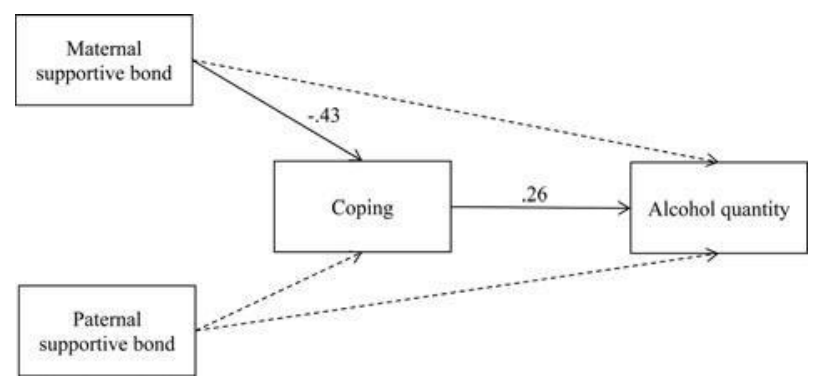

FIGURE 2. Mediation model for female adolescents (coping motive).

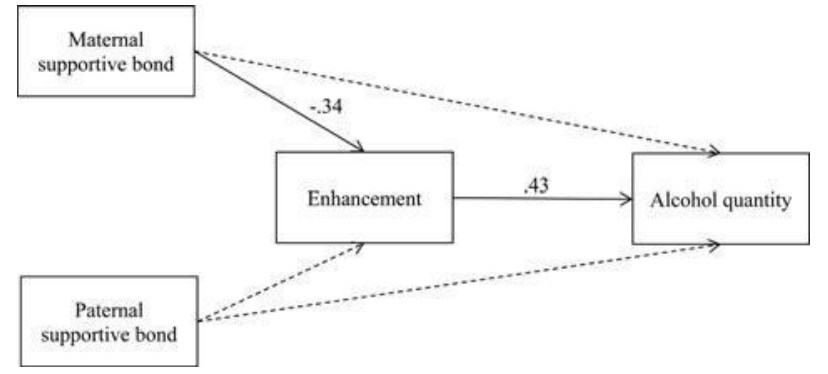

FIGURE 3. Mediation model for female adolescents (enhancement motive).

\section{DISCUSSION}

The aim of this study was to examine the relationships between a supportive parental bond, drinking motives, and alcohol use, with a focus on the role of mediation.

Results revealed no significant direct effects of the relationship with both mother and father on adolescents' alcohol use. Findings showed significant indirect effects of maternal bond on alcohol quantity. Specifically, for the quantity of alcohol used by adolescents, coping, enhancement, and social motives wholly mediated the link between the maternal bond and their children's drinking. In contrast, paternal bond did not predict drinking quantity, not even indirectly. Thus, the findings suggest that mothers may exert an indirect, rather than direct, influence on

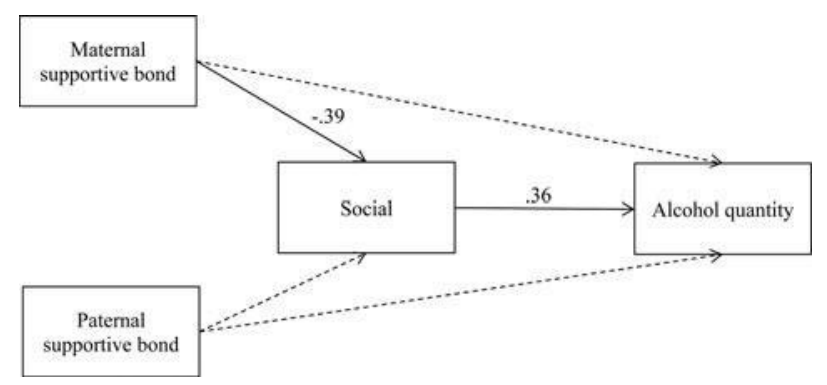

FIGURE 4. Mediation model for female adolescents (social motive). 
their children's drinking motives. These motives, in turn, predict the quantity of alcohol used by adolescents. No mediation effect was found for conformity motives. One possible explanation for this may be that, unlike for drink-ing to cope, for enhancement reasons, or for social rea-sons, drinking to conform cannot be easily observed and is rarely articulated (Muller \& Kuntsche, 2011).

Given that there were different results for the mater-nal and paternal bond, the findings indicate sex-specific effects of the parental bond on the quantity of alcohol used by adolescents. In particular, the findings highlight the central role of the mother in the parent-adolescent re-lationship. Consistent with previous studies, mothers are the relational fulcrum of the family, while fathers seem to maintain a more peripheral position (Greene \& Grimsley, 1990; Noller $\&$ Callan, 1990). This is even more salient in Italy, where the centrality of the mother is more empha-sised (Carra \& Marta, 1995; Malagoli-Togliatti \& Ardone, 1993) than it is in other cultures. In Italian families, be-sides the task of child-rearing, mothers also have the role of providing guidance, socialisation, and the transmission of norms and values (Manganelli and Capozza, 1993; Ros-nati, 1996; Scabini, 2000).

There are relevant gender differences in the model for the quantity of alcohol used by adolescents. Specifically, the results showed that mediation models were only supported among females. Thus, the combination of a good maternal bond and low drinking motives appears to be a protective factor for the development of adolescent female risky behaviors, such as alcohol use. On the contrary, a supportive maternal bond was associated with neither ado-lescent males' quantity of alcohol consumption nor with their drinking motives. In other words, mediation was not supported among males.

Overall, these results demonstrate that the quality of the maternal bond is more important in the lives of fe-males than in males in relation to adolescent alcohol consumption. A supportive bond between an adolescent female and her mother is a significant deterrent for alco-hol use but appears to have no effect on adolescent male behavior. One reason for these gender differences might be that parental socialisation processes operate differently for male and female adolescents. According to gender stereotypes, males are supposed to be adventurous, assertive, and independent, whereas females are considered to be more sensitive, dependent, emotional, and peopleoriented (Crespi, 2003). Further, females are expected not to do so, while males are encouraged to take risks (Simon $\&$ Corbett, 1996). On the basis of these gender stereo-types and roles, mothers may have different educational demands for their adolescent sons and daughters. Thus, it is possible that families tend to promote independence and autonomy in males and obedience in females (Lewis, 1986). These social and parental values and prescriptions are likely to be acquired from individuals and transformed into personal attributes, values, and self-regulated behav-iors. That is, adolescents internalise a set of standards, or attitudes, or motivations that will guide their behavior in new situations when their parents may not be present
(Grolnick et al., 1997). Further, given that females may be perceived as being more sensitive and confident, more ori-ented toward people, and consequently also easier to per-suade than males, it is likely that mothers also reinforce the motivations that allow their daughters to resist peer influence when they are away from the family context. After all, a warm parenting style plays an important role in fostering adolescent development and enhancing their motivational orientation (Bronstein, Ginsburg, \& Herrera, 2005).

In conclusion, even if heavy alcohol use generally takes place in the presence of the peer group, far from the family context, mothers continue to influence their daughters' behavior both through the values that they transmit to their female adolescents and through female adolescents' cognitions, which mothers instil in them. Conversely, since males are perceived by their parents as being more assertive, independent, and free in their decision-making, it is possible that parents do not believe that it is necessary to further reinforce their sons' motivational orientation.

Therefore for females, messages from mothers are likely to contribute to a heightened sense of personal responsibility for safe drinking. These differences in how family socialisation processes operate for males and females could account for the greater indirect influence of the parental bond on the drinking behaviors of females, compared to male adolescents. This finding is in line with the results of previous studies which have found that par-enting is more highly correlated with female risky behav-iors than with male risky behaviors (Browning, Leventhal, \& Brooks-Gunn, 2005; Loukas \& Prelow, 2004; Schinke et al., 2008).

Therefore, the present study provides support for the role of cognitive factors in the relationship between the maternal bond and the quantity of alcohol consumed by daughters. These findings are consistent with the assumptions of the motivational theories (Deci \& Ryan, 2000; Grolnick et al., 1997) regarding the role of cognitive factors in the link between parental practices and their children's drinking habits. Further, our results also provide evidence for the motivational model (Cooper, 1994; Cox \& Klinger, 1988), which assumes that more distal factors, including parenting, indirectly influence adolescent alcohol use through drinking motives.

However, there are also important differences between the two models for frequency and quantity of adolescent alcohol use. Specifically, contrary to the models for quantity of adolescent alcohol use, where a full mediation had been supported, no mediation by drinking motives was found for frequency of adolescent alcohol consumption, neither for males or females. One explanation for this may be ascribed to cultural reasons. It is possible that Italian mothers consider the quantity rather than the frequency of adolescent alcohol consumption to be a risk factor for their adolescent offspring that needs be largely regulated, indirectly, by themselves. Given that heavy drinking of-ten occurs outside the family context, together with the peer group (Graziano et al., 2011), mothers only indi-rectly affect the quantity of alcohol consumed by their 
daughters, by contributing to their drinking motivational orientation.

Taken together, our results indicate that a supportive maternal bond is a significant family-related factor in lim-iting excessive drinking in adolescence. For preventive ef-forts, it is therefore important to stress that by increasing adolescents' personal autonomy and providing them with support and warmth when needed, mothers have the op-portunity to actively minimise drinking motives and, in turn, the risk of excessive alcohol use by their female off-spring.

\section{Implications for Prevention}

Findings suggest that interventions aimed at simultaneously improving the quality of parental bonds and female motivational orientations are on the right track.

Therefore, attempts to change the quality of adolescent-parent relationships can be beneficial in reducing adolescent alcohol use. Further, our findings suggest that motivational orientation is a relevant protective factor for female, that is susceptible to change and that this should be the focus of prevention strategies.

After all, according to (MacKinnon, 1994), mediation analysis in prevention studies is relevant to delineate the processes that lead to changes of risky behavior. Analysis of targeted mediators, such as adolescent motivational orientation, hence might lead to the development of more effective prevention strategies.

\section{Limitations and Future Directions}

The present research study must be considered in light of a number of limitations. First, the present sample was relatively homogeneous in terms of age, race, and education levels, possibly limiting the degree to which the results can be generalized to similar-aged non-student popula-tions or to students with different ethnic characteristics. Further, the total variance for the quantity of adolescent alcohol use, explained by the indirect effect, was rela-tively small. This finding is not surprising given the multi-tude of antecedent factors for drinking motives (Kuntsche et al., 2006), such as personality (Mezquita, Stewart, \& Ruiperez,' 2010), parents' drinking habits (Muller \& Kuntsche, 2011) and peer influences (Kuntsche \& Stew-art, 2009) . Additional studies are needed to examine the stability of the present results when such covariates are included. In the present study we only used adolescents' self-reports to gather information. It would be of value to replicate these findings including other relevant sources of information, such as parent or peer reports. Finally, all the study variables were measured at the same time and did not allow for an investigation of the causal chain be-tween the parental bond, adolescent drinking motives, and adolescent alcohol use. Future research might attempt to evaluate whether a supportive parental bond changed ado-lescents' drinking motives, which in turn may change ado-lescent alcohol use over time.

In conclusion, the present study, conducted with a sample of Italian adolescents, provided evidence that mothers promote lower consumption of alcohol in their adolescent daughters through drinking motives. Though other factors may influence these links, drinking motives are a specific aspect of cognitive development that has been identified as a potential target for modification.

\section{Declaration of Interest}

The authors report no conflicts of interest. The authors alone are responsible for the content and writing of the article.

\section{GLOSSARY}

Drinking motives: Individual's reasons for engaging in al-cohol use. According to Motivational models, drinking motives are the most proximal factors to drink and they are important in both the initiation and perpetuation of that behavior.

\section{REFERENCES}

Adalbjarnardottir, S., \& Rafnsson, F. D. (2001). Perceived control in adolescent substance use: Concurrent and longitudinal analyses. Psychology of Addictive Behaviors, 15, 25-32.

Bahr, S., Marcos, A. \& Maughan, S. (1995). Family, educational and peer influences on the alcohol use of female and male ado-lescents. Journal of Studies on Alcohol, 56, 457-469.

Bandura, A. (1986). Social foundations of thought and action: A social cognitive theory. Englewood Cliffs, NJ: Prentice- Hall. 
Barbaranelli, C. (2007). Analisi dei dati. Tecniche multivariate per la ricerca psicologica e sociale, 2nd ed. Data analyses. Multi-variate techniques for psychological and social research. Mi-lano: LED.

Barnes, G. M., Reifman, A. S., Farrell, M. P., \& Dintcheff, B. A. (2000). The effects of parenting on the development of adolescent alcohol misuse: A six-wave latent growth model. Journal of Marriage and the Family, 62, 175-186.

Barnow, S., Schuckit, M. A., Lucht, M., John, U., \& Freyberger, H. J. (2002). The importance of a positive family history of alcoholism, parental rejection and emotional warmth, behavioural problems and peer substance use for alcohol problems in teenagers: A path analysis. Journal of Studies on Alcohol, 63(3), 305-315.

Baron, R. M., \& Kenny, D. A. (1986). The moderator-mediator vari-able distinction in social psychological research: Conceptual, strategic and statistical considerations. Journal of Personality and Social Psychology, 51, 1173-1182.

Beck, K. H., Boyle, J. R., \& Boekeloo, B. O. (2004). Parental monitoring and adolescent drinking: Results of a 12- month follow-up. American Journal of Health Behavior, 28(3), 272-279.

Bell, N. J., Forthun, L. F., \& Sun, S. W. (2000). Attachment, adolescent competencies and substance use: developmental consid-erations in the study of risk behaviors. Substance Use \& Misuse, 35(9), 1177-1206.

Bonaiuto, M., Perucchini, P., \& Pierro, A. (1997). L'adolescente e i membri significativi della sua rete sociale [The adolescent and significant members of his social network]. Et $a$ Evolutiva, 57, 40-56.

Bonino, S., Cattelino, E., \& Ciairano, S. (2005). Adolescents and risk. Behaviors, functions and protective factors. New York: SpringerVerlag.

Borawski, E. A., Ievers-Landis, C. E., Lovegreen, L. D., \& Trapl, E. S. (2003). Parental monitoring, negotiated unsupervised time, and parental trust: the role of perceived parenting practices in adolescent health risk behaviors. Journal of Adolescent Health, 33, 60-70.

Bronstein, P., Ginsburg, G. S., \& Herrera, I. S. (2005). Parental predictors of motivational orientation in early adolescence: A longitudinal study. Journal of Youth and Adolescence, 34(6), 559-575.

Browning, C. R., Leventhal, T., \& Brooks-Gunn, J. (2005). Sexual initiation in early adolescence: the nexus of parental and community control. American Sociological Review, 70, 758778.

Carra,` E. \& Marta, E. (1995). Relazioni familiari e adolescenza

[Family relationships and adolescence]. Milano: Franco Angeli. Cavallo, F., Lemma, P., Borraccino, A., Dalmasso, P., \& e Zambon, A. (2006). Stili di vita e salute dei giovani italiani tra 11-15 anni. Secondo rapporto sui dati italiani dello studio internazionale HBSC. [Second Italian Report of the Health Behaviours in School-aged Children Study].

Choo, H., \& Shek, D. (2013). Quality of parent-child relationship, family conflict, peer pressure, and drinking behaviors of adoles-cent in an Asian context: The case of Singapore. Social Indica-tors research, 110(3), 1141-1157.

Ciairano, S., Molinengo, G., Bonino, S., Miceli, R., \& van Schuur, W. (2009). Age of initiation with different substances and re-lationships with resources and vulnerabilities: A crossnational study. European Journal of Developmental Psychology, 6, 666-684.

Cooper, M. L. (1994). Motivations for alcohol use among adolescents: Development and validation of a four-factor-model. Psy-chological Assessment, 6(2), 117-128.
Cooper, M. L., Agocha, V. B., \& Sheldon, M. S. (2000). A motivational perspective on risky behaviors: The role of personality and affect regulatory processes. Journal of Personality, 68(6), 1058-1088.

Cox, W. M., \& Klinger, E. (1988). A motivational model of alcohol use. Journal of Abnormal Psychology, 97(2), 168-180.

Crawford, L. A., \& Novak, K. B. (2002). Parental and peer influences on adolescent drinking: the relative impact of attachment and opportunity. Journal of Child \& Adolescent Substance Abuse, 12(1), 1-26.

Crespi, I. (2003). Socialization and gender roles within the family: A study on adolescents and their parents in great Britain. http://www.iser.essex.ac.uk/bhps/2003/docs/pdf/paper/crespi. pdf

D'Alessio, M., Baiocco, R., \& Laghi, F. (2006). The problem of binge drinking among Italian university students: a preliminary investigation. Addictive Behaviors, 31, 2328-2333.

Deci, E. L. \& Ryan, R. M. (2000). The "what" and "why" of goal pursuits: Human needs and the self-determination of behavior. Psychological Inquiry, 11, 227-268.

DiGrande, L., Perrier, M. P., Lauro, M. G., \& Contu, P. (2000). Al-cohol use and correlates of binge drinking among university stu-dents on the Island of Sardinia, Italy. Substance Use \& Misuse, 35(10), 1471-1483.

Dishion, T. J., Nelson, S. E., \& Bullock, B. M. (2004). Premature adolescent autonomy: Parent disengagement and deviant peer process in the amplification of problem behaviour. Journal of Adolescence, 27, 515-530.

Fox, J. (2008). Applied regression analysis and generalized linear models. London: Sage Publications Inc.

Gmel, G., Rehm, J., \& Kuntsche, E. (2003). Binge drinking in Europe: Definitions, epidemiology, and consequences. Sucht, 49(2), 105-116.

Grant, V. V., Stewart, S. H., O’Connor, R. M., Blackwell, E., \& Conrod, P. J. (2007). Psychometric evaluation of the fivefactor modified drinking motives questionnaire - Revised in undergrad-uates. Addictive Behaviors, 32, 2611-2632.

Graziano, F., Bina, M., Giannotta, F., \& Ciairano, S. (2012). Drink-ing motives and alcoholic beverage preferences among Italian adolescents. Journal of Adolescence, 35, 823-831.

Greene, A. L., \& Grimsley, M. D. (1990). Age and gender differences in adolescents' preferences for parental advice: Mum's the world. Journal of Adolescent Research, 5, 396-413.

Griffin, K. W., Botvin, G. J., Epstein, J. A., Doyle, M. M., \& Diaz, T. (2000). Psychosocial and behavioral factors in early adolescence as predictors of heavy drinking among high school seniors. Jour-nal of Studies on Alcohol, 61, 603-606.

Grolnick, W. S., Deci, E. L., \& Ryan, R. M. (1997). Internalization within the family: The self determination perspective. In J. E. Grusec \& L. Kuczynski (Eds.), Parenting and children's internalization of values: A handbook of contemporary theory (pp. 135-161). New York: John Wiley \& Sons.

Ham, L. S., \& Hope, D. A. (2003). College students and problematic drinking: A review of the literature. Clinical Psychology Review, 23(5), 719-759.

Hingson, R. W., Zha, W., \& Weitzman, E. R. (2009). Magnitude of and trends in alcohol-related mortality and morbidity among US college students ages 18-24, 1998-2005. Journal of Studies on Alcohol and Drugs, 16, 12-20.

ISTAT (2010). http://www.istat.it/salastampa/comunicati/noncalendario/20100422_00/testointegrale20100422.pdf

Jessor, R., Donovan, J. E., \& Costa, F. M. (1992). Health behavior questionnaire. High school form. Colorado: University of Col-orado. 
Johnston, L. D., O’Malley, P. M., Bachman, J. G., \& Schulenberg, J. E. (2004). Monitoring the future national results on adolescent drug use: Overview of key findings, 2003 (No. NIH Publication No. 04-5506). Bethesda, MD7 National Institute on Drug Abuse.

Kairouz, S., Gliksman, L., Demers, A., \& Adlaf, E. M. (2002). For all these reasons, I do. . . drink: A multilevel analysis of con-textual reasons for drinking among Canadian undergraduates. Journal of Studies on Alcohol, 63(5), 600-608.

Kassel, J. D., Jackson, S. I., \& Unrod, M. (2000). Generalized expectancies for negative mood regulation and problem drinking among college students. Journal of Studies on Alcohol, 61(2), 332-340.

Kuntsche, E., Knibbe, R. A., Gmel, G., \& Engels, R. C. M. E. (2006). Why do young people drink? A review of drinking mo-tives. Clinical Psychology Review, 25(7), 841-861.

Kuntsche, E. N., \& Silbereisen, R. K. (2004) Parental closeness and adolescent substance use in single and two parent families in Switzerland. Swiss Journal of Psychology, 63(2) 85-92.

Kuntsche, E., \& Stewart, S. H. (2009). Why my classmates drink: Drinking motives of classroom peers as predictors of individual drinking motives and alcohol use in adolescence - a mediational model. Journal of Health Psychology, 14, 536-546.

Labouvie, E., \& Bates, M. E. (2002). Reasons for alcohol use in young adulthood: Validation of a three-dimensional measure. Journal of Studies on Alcohol, 63(2), 145-155.

Labrie, J. W., \& Sessoms, A. E. (2012). Parents still matter: The role of parental attachment in risky drinking among college students. Journal of Child \& Adolescent Substance Abuse, 21, 91-104.

Laghi, F., Baiocco, R., Lonigro, A., Capacchione, G., \& Baumgartner, E. (2012). Family functioning and binge drinking among Italian adolescents. Journal of Health Psychology, 17(8), 1132-1141.

Lewis, C. (1986). Early sex-role socialization. In D. J. Hargreaves \& A. M. Colley (Eds.), The psychology of sex roles (pp. 233249). London: Harper \& Row.

Li, X., Stanton, B., \& Feigelman, S. (2000). Impact of perceived parental monitoring on adolescent risk behavior over 4 years. Journal of Adolescent Health, 27(1), 49-56.

Loukas, A., \& Prelow, H. (2004). Externalizing and internaliz-ing problems in low-income Latino early adolescents: risk, resource and protective factors. Journal of Early Adolescence, 24, 250-273.

MacKinnon, D. P. (1994). Analysis of mediating variables in prevention and intervention research. NIDA Research Monograph, 139, 127-153.

MacKinnon, D. P., Fairchild, A. J., \& Fritz, M. S. (2007). Mediation analysis. Annual Review of Psychology, 58, 593-614.

Malagoli-Togliatti, M., \& Ardone, R. (1993). Adolescenti e genitori [Adolescents and parents]. Roma: La Nuova Italia Scientifica.

Manganelli, A. M., \& Capozza, D. (1993). Famiglia, ruoli sessuali, aspettative giovanili [Family, sex roles and juvenile expectations]. In M. Cusinato (Ed.), Ruoli e vissuti familiari (pp. 84-103). Firenze: Giunti.

Marcoulides, G. A., \& Hershberger, S. L. (1997). Multivariate sta-tistical method: A first course. Mahwah: Laurence Erlbaum As-sociates.

McArdle, P., Wiegersma, A., Gilvarry, E., Kolte, B., McCarthy, S., Fitzgerald, M., . . . Quensel, S. (2002). European adolescent sub-stance use: The roles of family structure, function and gender. Addiction, 97(3), 329-336.

McNally, A. M., Palfai, T. P., Levine, R. V., \& Moore, B. M. (2003). Attachment dimensions and drinking-related problems among young adults: The mediational role of coping motives. Addictive Behaviors, 28, 1115-1127.
Mezquita, L., Stewart, S. H., \& Ruiperez,' M. A. (2010). Big-five personality domains predict internal drinking motives in young adults. Personality and Individual Differences, 49, 240-245.

Muller, S., \& Kuntsche, E. (2011). Do the drinking motives of ado-lescents mediate the link between their parents' drinking habits and their own alcohol use?. Journal of Studies on Alcohol and Drug, 72, 429-437.

Muthen,' B. O., \& Kaplan, D. (1985). A comparison of some methodologies for the factor analysis of non-normal Likert vari-ables. British Journal of Mathematical and Statistical Psychol-ogy, 38, 171-189.

Muthen,' L. K., \& Muthen,' B. O. (1998/2007). Mplus user's guide (5th ed.). Los Angeles: Muthen' \& Muthen'.

Noller, P., \& Callan, V. J. (1990). Adolescents' perceptions of the nature of their communication with parents. Journal of Youth and Adolescence, 19, 349-362.

Parker, G. (1989). The parental bonding instrument: Psychometric properties reviewed. Psychiatric Developments, 4, 317-335.

Parker, G., Tupling, H., \& Brown, L. B. (1979). A parental bonding instrument. British Journal of Medical Psychology, 52, 1-10.

Patock-Peckham, J. A., Cheong, J., Balhorn, M. E., \& Nagoshi, C. T. (2001). A social learning perspective: A model of parenting styles, self-regulation, perceived drinking control, and alcohol use and problems. Alcoholism: Clinical and Experimental Re-search, 25(9), 1284-1292.

Patock-Peckham, J. A., \& Morgan-Lopez A. A. (2006). College drinking behaviors: Mediational links between parenting styles, impulse control, and alcohol-related outcomes. Psychology of Addictive Behaviors, 20(2),117-25.

Perkins, H. W. (2002). Surveying the damage: A review of research on consequences of alcohol misuse in college populations. Jour-nal of Studies on Alcohol, 14, 91-100.

Read, J. P., Wood, M. D., Kahler, C. W., Maddock, J. E., \& Palfai, T. P. (2003). Examining the role of drinking motives in college student alcohol use and problems. Psychology of Addictive Be-haviors, 17, 13-23.

Roche, K. M., Ahmed, S., \& Blum, R. W. (2008). Enduring consequences of parenting for risk behaviors from adolescence into early adulthood. Social Science \& Medicine, 66, 2023-2034.

Rosnati, R. (1996). Gender differences and adolescent life plans: A family point of view. In M. Cusinato (Ed.), Research on family resources and needs across the world (pp. 375-394). Padova: LED.

Scabini, E. (2000). Parent-Child Relationships in Italian Families: Connectedness and Autonomy in the Transition to Adulthood. Psicologia: Teoria e Pesquisa, 16, 23-30.

Schinke, S. P., Fang, L., \& Cole, K. C. A. (2008). Substance use among early adolescent girls: Risk and protective factors. Jour-nal of Adolescent Health, 43,191-194.

Simon, F.. \& Corbett, C. (1996). Road traffic offending, stress, age, and accident history among male and female drivers. Ergonomics, 39, 757-780.

Thomas, G., Reifman, A., Barnes, G. M., \& Farrell, M. P. (2000). Delayed onset of drunkenness as a protective factor for adolescent alcohol misuse and sexual risk taking: Longitudinal study. Deviant Behaviour, 21(2), 181-210.

Tucker, J. S., Orlando, M., \& Ellickson, P. L. (2003). Pat-terns and correlates of binge drinking trajectories from early adolescence to young adulthood. Health Psychology, 22, 7987.

Turrisi, R., Mallett, K. A., Mastroleo, N. R., \& Larimer, M. E. (2006). Heavy drinking in college students: Who is at risk and what is being done about it? Journal of General Psychology, 133(4), 401-420. 
Turrisi, R., Wiersma, K. A., \& Hughes, K. K. (2000). Binge drinking-related consequences in college students: Role of drinking beliefs and mother-teen communications. Psychology of Addictive Behaviours, 14(4), 342355.

Vermeulen-Smit, E., Ter Bogt, T. F. M., Verdurmen, J. E. E., Van Dorsselaer, S. A. F. M., \& Vollebergh, W. A. M (2012). The role of education, parents and peers in adolescent heavy episodic drinking. Drugs: Education, Prevention \& Policy, 19(3), 223-226.

Zogmaister, C., \& Castelli, L. (2011). Perche' i giovani bevono? Versione italiana del DMQ-R (Cooper, 1994), strumento per l'indagine della motivazione al consumo di alcolici [Why do youngsters drink? Italian version of the DMQ-R (Cooper, 1994), questionnaire for the assessment of drinking motives]. Psicolo-gia della Salute, 1, 101-118. 